\title{
Measurement techniques for in situ stresses around underground constructions in a deep clay formation
}

\author{
J. Verstricht ${ }^{1, \mathrm{a}}$, L. Areias ${ }^{1}$, W. Bastiaens ${ }^{1}$, and X.L. $\mathrm{Li}^{1}$ \\ ${ }^{1}$ EIG EURIDICE, c/o SCK•CEN, Boeretang 200, 2400 Mol, Belgium
}

\begin{abstract}
Disposal in deep underground geological formations is internationally recognized as the most viable option for the long-term management of high-level radioactive waste. In Belgium, the Boom clay formation is extensively studied in this context, in particular at the $225 \mathrm{~m}$ deep HADES Underground Research Facility in Mol. A cost-effective design of deep underground structures requires an accurate assessment of the in situ stresses; a good estimation of these stresses is also essential when interpreting in situ experiments regarding the hydro-mechanical behaviour of the host formation. Different measurement techniques are available to provide data on the stress evolution and other mechanical properties of the geological formation. The measurement can be direct (measurement of total pressure), or it can be an indirect technique, deriving the stress from related quantities such as strain (changes) in structural members. Most total stress measurements are performed through permanently installed sensors; also once-only measurements are performed through specific methods (e.g. pressuremeter). Direct measurement of the stress state is challenging due to the complex mechanical behaviour of the clay, and the fact that the sensor installation inevitably disturbs the original stress field. This paper describes ways to deal with these problems and presents the results obtained using different techniques at HADES.
\end{abstract}

\section{Context}

Disposal of high-level radioactive waste in deep underground geological formations is internationally recognized as the most viable option. In Belgium, the Boom clay formation is extensively studied in this context since the early 1970's. This formation is a sedimentary clay deposit from the early Oligocene (36-30 My) and extends over a large part the NE of Belgium and further at the neighbouring countries. At the Nuclear Research Centre (SCK•CEN) in Mol, the formation is about $100 \mathrm{~m}$ thick and the top is about $180 \mathrm{~m}$ deep. The construction of the Underground Research Facility, called HADES, started in 1980 with the sinking of the first shaft up to $223 \mathrm{~m}$ deep; the most recent addition (PRACLAY gallery) dates from 2007 (Figure 1). The construction works in the 1980's were mainly feasibility oriented. With the experience gained, the extension works that started with the second shaft in 1997 allowed to optimise the construction works through industrial excavation and lining techniques. Optimisation refers to both the

a e-mail : jan.verstricht@sckcen.be

This is an Open Access article distributed under the terms of the Creative Commons Attribution-Noncommercial License 3.0, which permits unrestricted use, distribution, and reproduction in any noncommercial medium, provided the original work is properly cited. 
dimensioning of the underground structures, as to minimising the disturbance (e.g. fracturing) of the host clay formation due to the underground construction works.

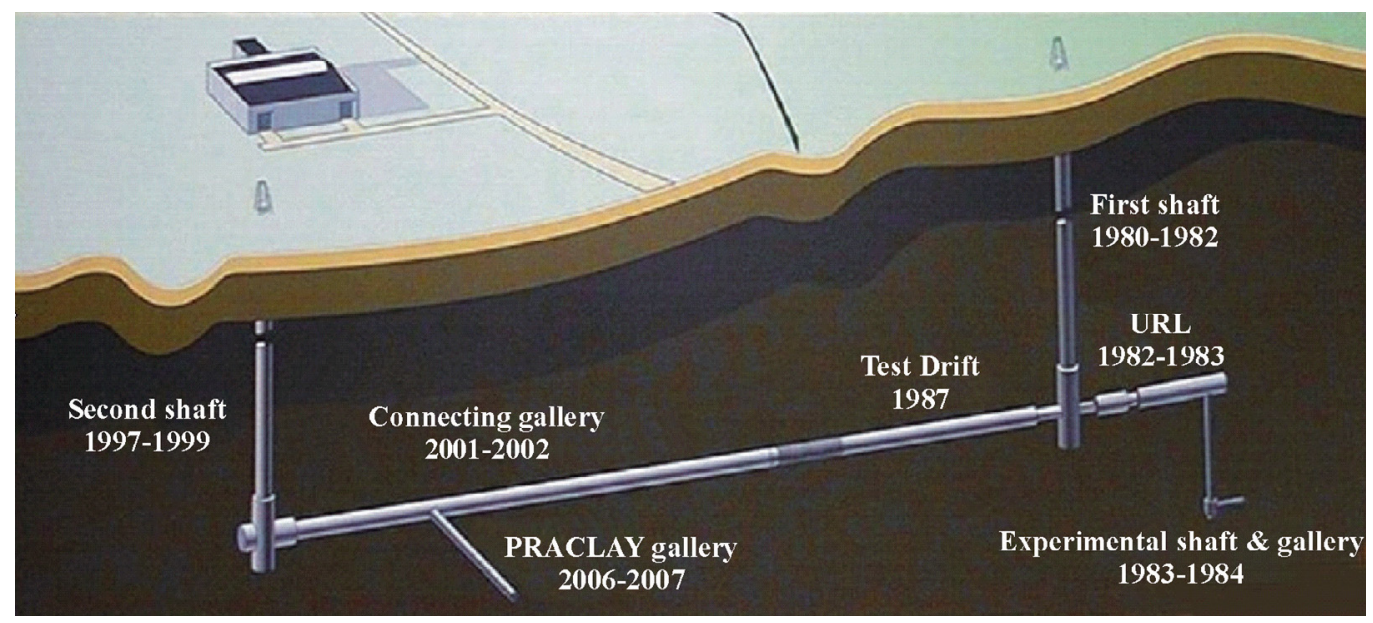

Fig. 1. Construction and extension of the Underground Research Facility HADES.

Firstly, a thorough knowledge of the underground total stress is needed for the design and implementation of underground structures. The original total stress can be roughly estimated by the overburden (about 4.5 MPa in the case of HADES). The in situ stress state is slightly anisotropic: the vertical stress is estimated to be slightly larger than the horizontal stress components $\left(\mathrm{K}_{0} \approx 0.85-0.9\right.$ in total stress) [1]. An underground excavation alters the stress state significantly, with the extent depending on e.g. the applied excavation process and lining technique.

Models are available to predict these stress evolutions, taking into account both the host rock behaviour and the construction activities. Clay behaves in a complex way with a particular elastic, plastic and viscous behaviour. The low hydraulic permeability further causes a strong coupling of the total stress with the porewater pressure evolution $[2,3]$.

In situ monitoring of the total stress is therefore useful for a cost-effective design of underground structures and to better understand the influence of the underground activities on the host clay formation; it further helps to refine the model predictions employed in the design process.

\section{Measurement Techniques}

Direct measurement of the total stress inside a soil/rock is a challenging task due to the very nature of the concept "stress", and due to practical reasons such as the disturbance caused by sensor installation. The stress, represented by a tensor, can be estimated by measuring the pressure in different directions. Methods to determine the original stress state have been developed for elastic materials and are based on the strain relief of a sample upon removal of the external stress. These methods involve attaching a strain cell (e.g. "Doorstopper") to the borehole wall or bottom; the strain relief recorded when overcoring this borehole gives then an indication of the in situ stress. This measurement principle supposes a linear elastic rock, intact cores are needed for a full interpretation, and the gluing procedure usually requires an appropriate surface [4]. Because of these limitations, it is not likely to function in Boom Clay, which behaves far away from an elastic rock, and has therefore not been tried. Indirectly, strain relief has been observed through e.g. borehole break-outs and the immediate convergence when tunnelling. A modified technique is the application of a compensating pressure and monitoring the related strains. Methods based on this principle are the pressuremeter (optionally self-boring to minimise installation disturbance) and dilatometer. Also, the hydraulic fracturing method can be classified here. Usually, these methods are once-only tests. 
When a continuous monitoring of the stress is desired, a relative measurement (stress change) is the most realistic. Monitoring of the in situ stress requires installation of stress sensors in boreholes. Such a sensor typically consists of several pressure cells mounted in different directions to monitor different components of the stress tensor. Usually the most important components are monitored based on assumptions of the site conditions (e.g. isotropy of horizontal stress). Due to the strong hydro-mechanical coupling in clay, the porewater pressure (evolution) also gives a representative image of the total stress evolution, in particular at short term [3].

In soil mechanics, stress is usually monitored through specific pressure sensors. The specific thing lies usually in the enlarged pressure sensitive plate (known as membrane or diaphragm) due to the larger aggregates often encountered in soils and similar materials. Particular attention should also be paid to the sensor stiffness compared to the soil stiffness. The mostly used pressure cell is based on a flatjack cell, in which the soil pressure is converted into a fluid pressure (mercury, oil or water), which on its turn can be measured by more or less conventional (i.e. specifically used in geotechnical environments such as vibrating wire) techniques.

When installing sensors in boreholes, backfilling of the hole might be required; the characteristics of this backfill already determine strongly the later pressure cell behaviour. Therefore, we integrate several flatjacks into a cylindrical device to avoid the use of backfill.

When dealing with the stress acting on structural parts (shaft and gallery lining), more solutions are available: the gallery lining itself can be considered as stress transducer (by monitoring its deformation), or pressure sensors can be integrated in these elements.

\section{Monitoring cases}

The results of three measurement techniques are discussed: (1) direct measurement of total stress through borehole sensors; (2) stresses derived from lining strains, and (3) borehole test methods: (self-boring) pressurementer, dilatometer and hydraulic fracturing ("hydrofrac").

\subsection{Borehole stress cells}

Several boreholes drilled from the Connecting Gallery (CG) and from the PRACLAY Gallery (PG) have been instrumented with flatjack type stress sensors, each consisting of four flatjack type cells mounted on a cylindrical device (Figure 2). The boreholes from the CG were drilled and instrumented prior to the excavation and lining of the PG.

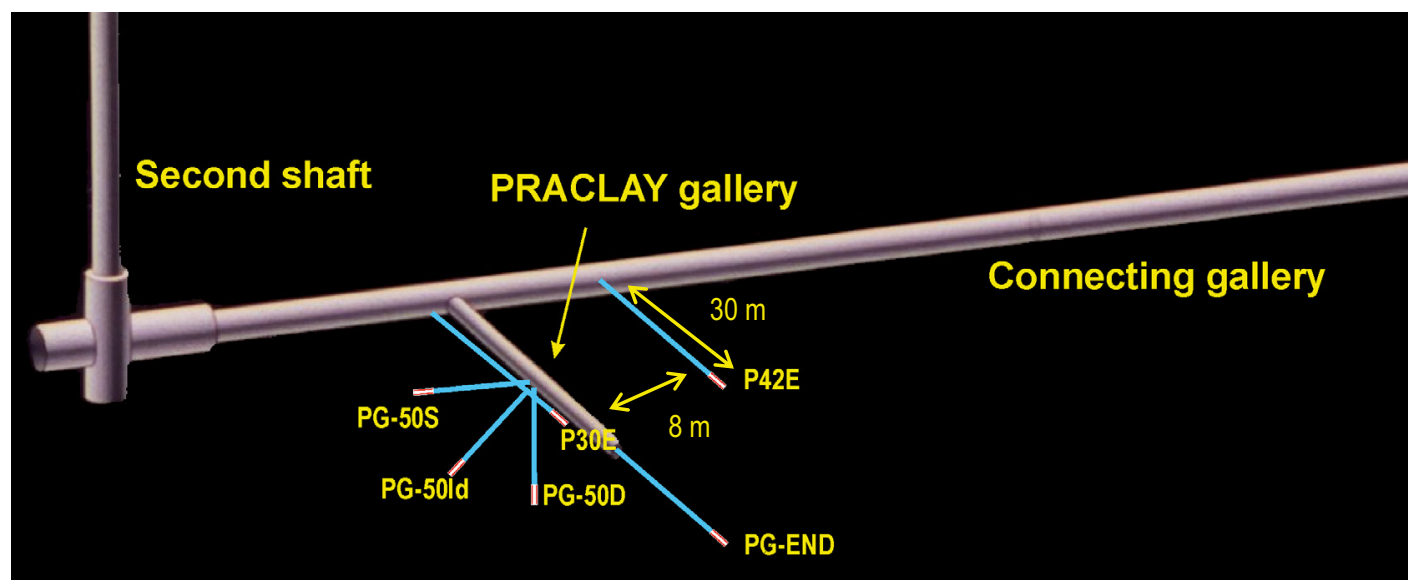

Fig. 2. Location of the flatjack type stress cells around the Connecting and PRACLAY galleries. 
The pressure indicated by these sensors shows an initial pressure build-up due to the borehole convergence; the CG sensors further recorded the stress change due to the PG excavation and lining. As an example, Figure 3 shows the total stress evolution recorded by the flatjacks of P42E, as well as the porewater pressure. Figure 3 a shows the borehole convergence followed by the stress changes due to the PG excavation; Figure $3 \mathrm{~b}$ highlights the change during and after the PG excavation and lining. The total pressure evolution shows a limited change in the effective stress, it is only slightly larger $(<0.5 \mathrm{MPa})$ than the water pressure. The total pressure evolution differs according to the orientation: the horizontal pressures show a large dip when the excavation front passes the plane of the sensor; this dip is hardly noticeable in the vertical components, which show a steep increase, as predicted by models analysing the stress redistribution around excavations. Comparison with the porewater pressure further shows a consolidation (draining by PG).
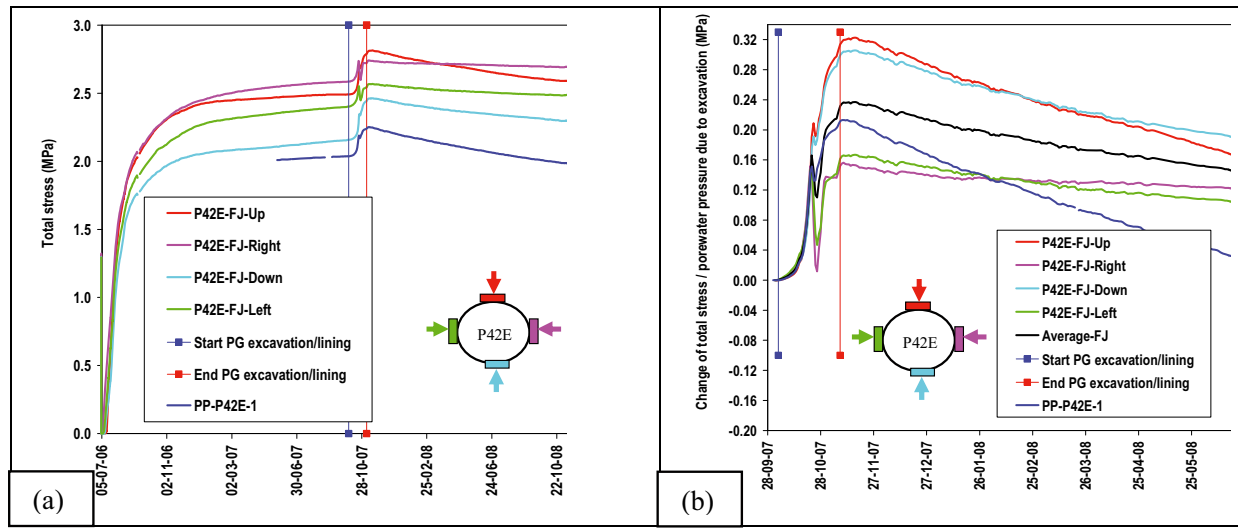

Fig. 3. Total pressure evolution of sensor P42E; (a) overall evolution, (b) changes due to PRACLAY gallery excavation.

The sensor in borehole P30E, about $1 \mathrm{~m}$ under the PG, shows a similar overall pressure evolution (Figure 4), including the consolidation effect. The stress change due to the PG excavation is however different from those sensors located in a horizontal plane of the PG. This is due to the anisotropy of the in situ stress state and probably also due to the anisotropic behaviour of the Boom clay itself.

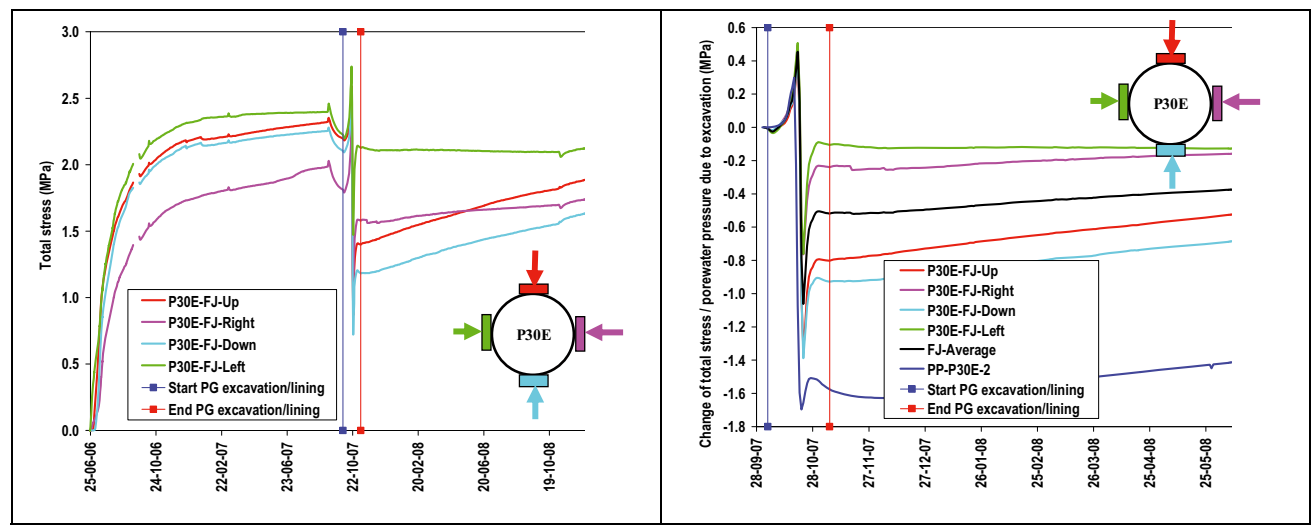

Fig. 4. Pressure evolution of the flatjack device of borehole P30E (left: overall evolution, right: changes due to PRACLAY gallery excavation). 
The stress devices in the boreholes drilled from the PG show a similar overall pressure evolution (Figure 5): a rather limited total pressure changes, and a large divergence between the individual sensors. In addition, a decreasing trend shows up, probably due to the draining effect of the PG which is a relatively slower phenomenon due to the low permeability of the Boom Clay.

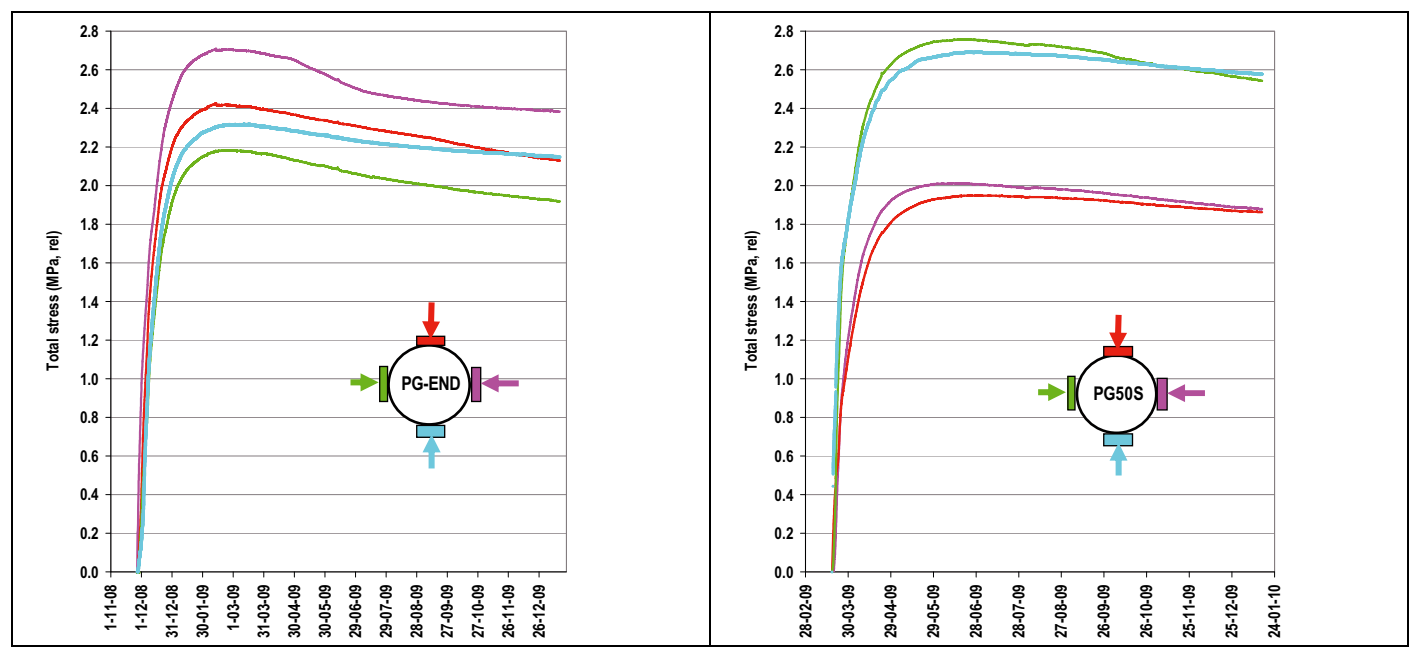

Fig. 5. Pressure evolution of the flatjack device of borehole PG-END (left) and PG50S (right).

\subsection{Stress on gallery lining}

In both the CG and the PG, several lining segments have been instrumented with strain gauges. These measure the circumferential strain; the gauges are installed both at the inside and outside of the segment, so that also bending moments can be monitored. Figure 6 shows the configuration for an instrumented ring in the $\mathrm{CG}$, consisting of 10 strain gauged segments, together with a picture of an instrumented segment being cast.
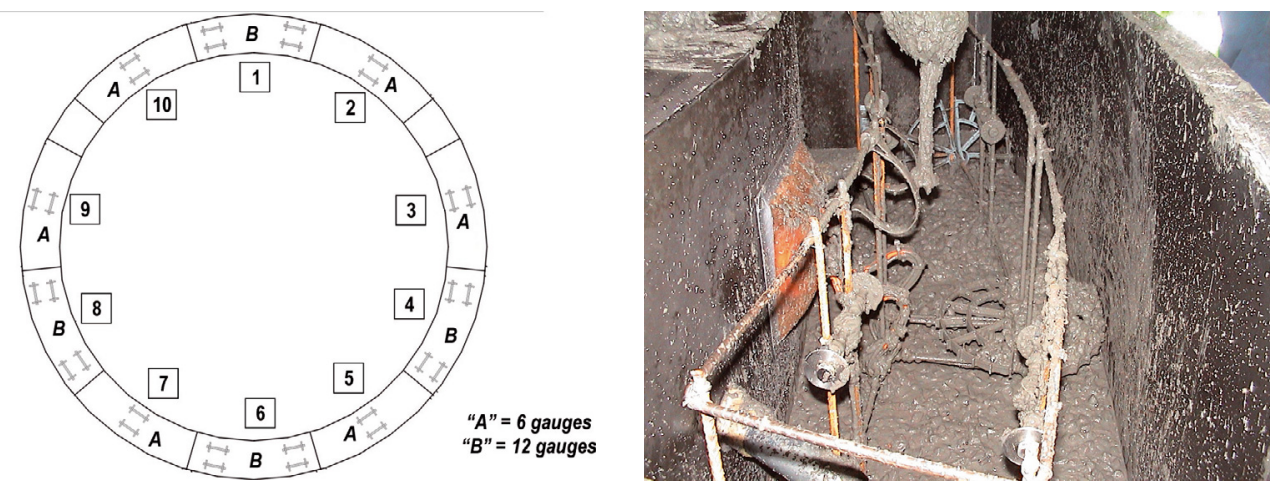

Fig. 6. Configuration of strain gauged segments in the CG (left); instrumented cage to be placed in segment mould prior to concreting (right).

The strain evolution within two segments (9 and 10) is shown in Figure 7. The pressure builds up quite rapidly - a significant part already within the first 24 hours. This shows the performance of the lining technique (expanded wedge blocks lining) in which the clay wall is supported immediately after installation of the lining segments, thereby minimising the excavation damaged zone. Most 
segments also show a distinctive strain evolution for the gauges mounted at the inside and at the outside of the segments, indicative for bending in the segments.

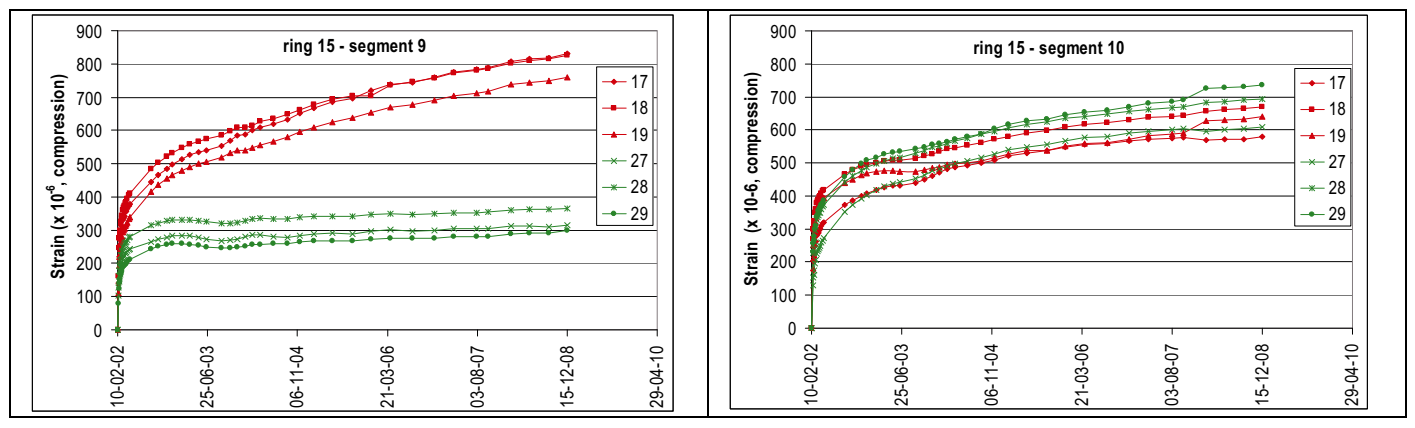

Fig. 7. Strain evolution within two segments in ring 15.

From the averaged strains, the external pressure can be derived based on a simple averaging and thin wall approximation. Similar results are obtained for the rings 30 and 50. However, a more detailed analysis of the external pressures evolution should take also into account the creep characteristics of the wedge block concrete at long term (with decreasing effective elastic modulus). A detailed investigation considering the measurements of the first year results in a pressure between 2.1 and 3.1 $\mathrm{MPa}[5]$.

\subsection{Borehole tests}

Active tests methods applying a pressure and observing the result (deformation of the borehole wall through a packer, or fracturing when applying a fluid pressure between packers) allow to obtain various mechanical soil/rock properties. It normally also includes an assessment of the in situ stress. The tests carried out at HADES include both self-boring pressuremeter tests and hydrofrac measurements.

\subsubsection{Self-boring pressuremeter (SBPM) and High pressure Dilatometer (HPD) tests}

The SBPM test is an adapted version of the pressuremeter and dilatometer tests to minimise the disturbance of the installation on the in situ stress compared. In this set-up, the pressuremeter (an instrumented packer to observe the borehole deformation at different orientations) is mounted on top of a drill rig to minimise borehole disturbance prior to testing. Table 1 lists the different tests that have been carried out at HADES to cover the subsequent construction and exploitation phases, in particular with relation to the CG excavation (carried out in 2002).

During the last campaign we could compare the SBPM with the HPD in a predrilled hole. Figure 8 shows the results for the vertical hole; apart from the initial point (pressure development) which reflects the gap between the pre-drilled hole and the tool diameter, both curves are remarkably similar. Due to the pre-drilling, the HPD can be carried out much faster, thereby yielding a larger pressure capacity than the SBPM. The HPD method was therefore used in the next (horizontal) borehole. The stress anisotropy (horizontal/vertical) caused however a collapse of the borehole, which was not the case in a vertical borehole, giving a very strong indication of the $\mathrm{K}_{0}$.

Generally, the results of pressuremeter tests indicate strength and in situ stress levels consistent with local measurements and laboratory testing results. The interpretation of the subsequent test campaigns indicates however the importance of the test conditions and, borehole orientations (reflecting the anisotropy of the clay properties), and is still a domain of intensive research [6]. 
Table 1. SBPM and HPD test campaigns in HADES.

\begin{tabular}{|c|c|}
\hline $\begin{array}{l}1999 \text { (prior to } \mathrm{CG} \\
\text { construction) }-\mathrm{SBPM}\end{array}$ & $\begin{array}{l}\text { Between } 20 \text { and } 30 \mathrm{~m} \text { deep in horizontal borehole near } \mathrm{CG} \text { axis; in situ } \\
\text { stress around } 3.4 \mathrm{MPa} \text { with small anisotropy; effective stress around } \\
2.0 \mathrm{MPa} \text {. }\end{array}$ \\
\hline $\begin{array}{l}2002 \text { (1 month after CG } \\
\text { construction) - SBPM }\end{array}$ & \multirow{2}{*}{$\begin{array}{l}\text { Same geometry for both tests: horizontal borehole, up to } 12 \mathrm{~m} \text { deep; } \\
\text { increase of total stress between both campaigns; influence of CG only } \\
2-3 \mathrm{~m} \text { deep for material parameters (shear strength, shear modulus) } \\
\text { with no apparent change (high repeatability). }\end{array}$} \\
\hline $\begin{array}{ll}2004 & (2.5 \text { years after } \\
\text { CG construction }) \quad- \\
\text { SBPM }\end{array}$ & \\
\hline $\begin{array}{l}2009 \text { - both SBPM and } \\
\text { HPD }\end{array}$ & $\begin{array}{l}\text { Inclined, vertical and horizontal borehole (later ones with HPD instead } \\
\text { of SBPM); vertical and horizontal boreholes behave different - clear } \\
\text { indication of } \mathrm{K}_{0} \text { and anisotropic mechanical characteristics of Boom } \\
\text { clay. Effective stresses slightly above } 2.0 \mathrm{MPa} \text {. }\end{array}$ \\
\hline
\end{tabular}

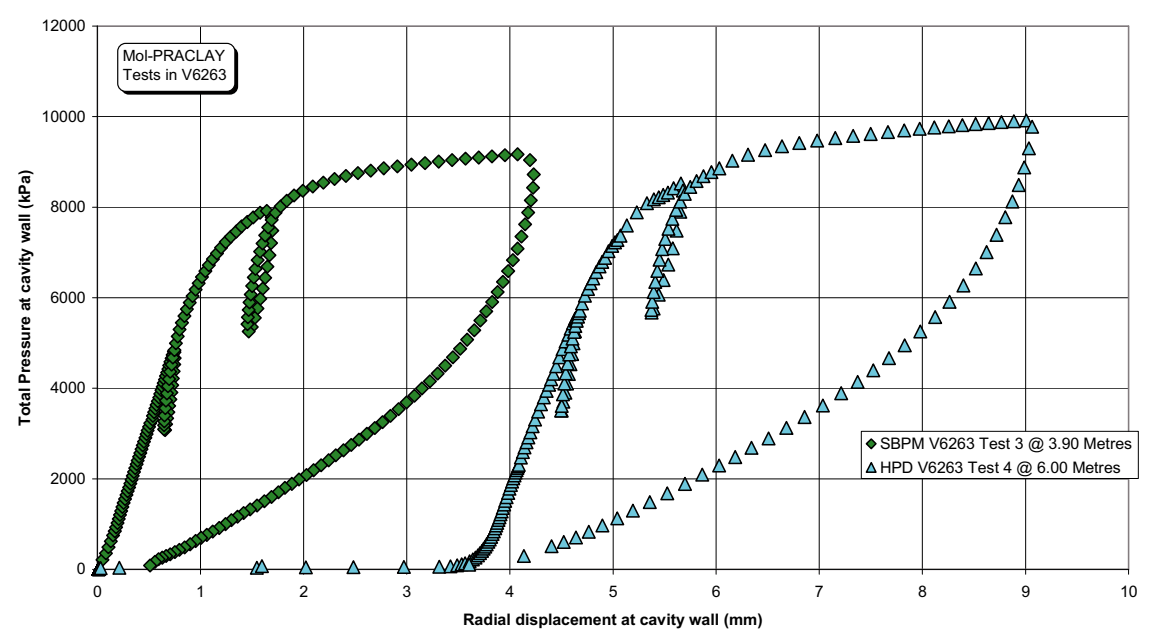

Fig. 8. Self-Boring Pressuremeter (SBPM) compared with a high pressure dilatometer (HPD);

\subsubsection{Hydraulic fracturing tests}

This method consists in isolating a borehole section with packers, applying a fluid (usually water) pressure to this section until a breakdown (sudden flow increase) occurs, followed by a shut-in test. Finally, imaging of the borehole wall allows the characterisation of the fractures with their orientation and hence the minor principal stress directions.

A first test campaign was performed as part of the test programme linked with the excavation of the CG in 1999 inside a horizontal borehole. None of the tests showed the initiation of new fractures, however reliable shut-in pressure data were obtained. Imaging of the borehole through impression packer showed that axial, sub-vertical fractures were stimulated. The minimum horizontal and vertical stresses derived were 2.5 and 5.2 MPa, respectively. Short pressure pulse tests prior to the hydrofrac tests yielded a rather high hydraulic conductivity, indicating a damaged borehole wall due to the drilling process. To improve the test performance, water was substituted by a (biodegradable) oil in a next campaign (2009), as clay contains swelling materials that readily react with water. As in the previous campaign, we lacked clear breakdown pressures: the packers were inflated at low 
pressures - in order not to exceed the yield strength of the clay at the borehole wall, and therefore only a small injection rate could be applied. However, consistent values of shut-in pressures were obtained in all tests. Interpretation of these test results revealed however delicate. Nevertheless, the accompanied borehole television imagining analysis and borehole convergence measurement indicated a sub-equal maximum and minimum horizontal stress in Boom clay. An order of value of $\mathrm{K}_{0}$ between 0.83-0.88 (total stress) was obtained.

\section{Conclusions}

The assessment of the in situ stress requires different sensor types and test methods to be deployed. These deliver us different results, each requiring a proper interpretation depending in the measurement technique. Borehole sensors are able to show a continuous picture with time, but due to their installation already they do not give a representative picture of the in situ stress - usually the pressures observed are lower than what can be expected based on the overburden stress. The results obtained by the "active" borehole methods give values which are more close to the expected values. A detailed test procedure adapted to the host rock is essential to obtain reliable measurement results.

Based on all the experiences, we envisage several approaches to improve the reliability of these measurements; they include a regular and systematic update of all results obtained by the different methods, a numerical simulation of the measurement performance (e.g. inclusion effect of a stress cell installed in clay with a specific strength), a further exploitation of measuring instruments adapted to the clay so that the reliability of our image of the in situ stress and its changes (construction and exploitation related) can be improved.

Finally, an integrated analysis combining all observations (borehole break-outs, back-analysis of the in situ testing, etc. ) is essential to get a good estimation of the in-situ stresses in HADES.

\section{References}

[1] S. T. Horseman, M.G. Winter, D.C. Entwistle. Geotechnical characterisation of the Boom Clay in relation to the disposal of radioactive waste. Final report. Report EUR 10987. (Luxembourg: Commision of the European Communities, 1987)

[2] W. Bastiaens, F. Bernier, X.L. Li. SELFRAC: experiments and conclusions on fracturation and self-healing and self-sealing processes in clays. Applied clay science, Clays in Natural \& Engineered Barriers for Radioactive Waste Confinement. Proc. Int. Symp., Tours, 14-18 March 2005. (Amsterdam: Elsevier, 2005).

[3] W. Bastiaens, F. Bernier, X.L. Li. An overview of long-term HM measurements around HADES URF. EUROCK 2006 - Multiphysics Coupling and Long Term Behaviour in Rock Mechanics. (Van Cotthem, Charlier, Thimus \& Tshibangu (eds). Taylor \& Francis Group, London, 2006).

[4] B. Amadei, O. Stephansson. Rock stress and its measurement (Chapman \& Hall, 1997).

[5] C. Ramaeckers, A. Van Cotthem. Analysis of the instrumented rings. Internal report (Brussels: Belgatom, 2003).

[6] X.L. Li, L. Areias, F.H. Cornet, B. Célérier, R.W. Whittle, W. Bastiaens. Recent Test program for In situ stress determination/estimation in the Boom Clay at the HADES Underground Research Laboratory in Mol, Belgium. Clays in Natural \& Engineered Barriers for Radioactive Waste Confinement, $4^{\text {th }}$ International Meeting, 29 March-1 April 2010. (ANDRA, 2010). 
Bestandsnaam:

Map:

ICEM_paper_final.doc

Sjabloon:

$\mathrm{H}:$

Data $\backslash$ Microsoft $\backslash$ Sjablonen $\backslash$ Normal.dot

Titel:

This space should be left blank, except for the name of the first author. (The publisher will re-type the main title, author names and addresses.

Please give this information on a separate page.)

Onderwerp:

Auteur:

Houlbert

Trefwoorden:

Opmerkingen:

Aanmaakdatum:

5-4-2010 9:14

Wijzigingsnummer: 5

Laatst opgeslagen op: 5-4-2010 9:42

Laatst opgeslagen door:

Totale bewerkingstijd: 42 minuten

Laatst afgedrukt op: $\quad$ 5-4-2010 10:08

Vanaf laatste volledige afdruk

Aantal pagina's: 8

Aantal woorden: 3.086 (ong.)

Aantal tekens: 16.979 (ong.) 